\title{
LÓGICAS DECISÓRIAS E SUAS IMPLICAÇÕES PARA A SUSTENTABILIDADE NAS ORGANIZAÇÕES
}

\author{
Decisional logic and its implications for sustainability in organizations
}

Luisa Maria Sarábia-Cavenaghi*
Luciano Munck**

\section{RESUMO}

O estudo e a compreensão sobre a principal lógica que orienta o processo decisório nas organizações incitam a discussão sobre a existência, ou não, de coerência entre agires organizacionais como definição de objetivos e estratégias e a construção de organizações sustentáveis. A partir dessa reflexão será possível identificar se as ações e decisões organizacionais consideram fatores ambientais, sociais e econômicos concomitantemente, se refletem sobre trade-offs e se visam ao longo prazo. Os autores desse artigo acreditam que uma organização que toma decisões avaliando todos esses aspectos pode ser considerada sustentável. A partir daí será possível antever, traduzir ou rever as consequências das escolhas no curto, médio e longo prazos. Nesse sentido, este artigo foi desenvolvido com o intuito de ampliar o debate e a compreensão sobre como as lógicas decisórias adotadas pelos gestores acabam por determinar os agires organizacionais, os quais podem ou não legitimar os anseios da sustentabilidade corporativa. Inicialmente, elabora-se e apresenta-se reflexões sobre abordagens e lógicas decisórias que podem estar subsidiando as decisões sobre sustentabilidade nas organizações. $\mathrm{Na}$ sequência, apresenta-se um quadro teórico sintético que propõe as combinações entre abordagens e perspectivas decisórias referentes a sustentabilidade, bem como, apresenta as implicações de cada combinação sugerida para a gestão nas organizações. A partir do quadro são tecidas análises e reflexões sobre como as lógicas decisórias acabam por determinar resultados positivos ou negativos para aquelas organizações que se declaram sustentáveis.

Palavras-chave: Lógicas decisórias. Sustentabilidade. Organizações.

\begin{abstract}
The study and the comprehension of the main logic that guides the decision-making process incites the discussion about the existence or not of coherence in organizational actions. Based on this information, we propose that it will be possible to analyze whether organizational actions and decisions towards sustainable development consider environmental, social and economic factors simultaneously. This will make possible to anticipate, translate and revise their short, medium or long-term consequences in view of decision-making logic choices. Considering this context, this article was developed with the aim of broadening the debate and the understanding of how the decision-making logic adopted by organizational managers end up determining the actions that aim at corporate sustainability. Initially, this article presents and elaborates reflections on approaches and decision-making logic that may be subsidizing decisions about sustainability in organizations. From this, it presents a synthesis of a theoretical framework that proposes the combination between approaches and decision-making perspectives regarding sustainability as well as the implications of each combination suggested for management in organizations. From the suggested framework, we analyze and reflect on how decision-making logic ultimately determines positive or negative results for those organizations that declare themselves sustainable.
\end{abstract}

Keywords: Decision logic. Sustainability. Organizations.

\footnotetext{
* Mestre em Administração pela Universidade Estadual de Londrina (UEL). Professora da Universidade Norte do Paraná (Unopar) - Londrina (PR), Brasil. E-mail: luisasarabia@hotmail.com. ORCID: 0000-0002-6017-2600

** Pós-Doutor pelo Building Sustainable Value Research Centre, Ivey Business School, Western University (Canadá). Doutor em Administração pela Universidade de São Paulo (USP). Professor da Universidade Estadual de Londrina (UEL) - Londrina (PR), Brasil. E-mail: munck@uel.br. ORCID: 0000-0001-5851-6315
} 


\section{INTRODUÇÃO}

A s preocupações e debates relacionados à sustentabilidade, tais como o limite de recursos ou a capacidade de resistência às diversas agressões dos sistemas ambientais, vêm de longa data. Riscos relacionados à poluição, ao desmatamento, à degradação do solo ou à adulteração de alimentos sempre existiram em menor ou maior proporção, no entanto, as últimas décadas foram marcadas por um crescimento econômico mundial que ignorou seus efeitos colaterais, fazendo todos os riscos citados e outros não mencionados aumentarem consideravelmente. Com isso, as discussões sobre sustentabilidade e seus desafios avançaram, principalmente a partir da criação da Comissão Mundial sobre o Meio Ambiente e Desenvolvimento (CMMAD), tendo como principal contribuição a criação do Relatório Nosso Futuro Comum (Our Common Future), em 1987, que trouxe um diagnóstico rigoroso em relação ao estado do meio ambiente (MEBRATU,1998). Foi por meio dele que se estabeleceu a principal definição de "desenvolvimento sustentável": "O desenvolvimento que satisfaz as necessidades das gerações atuais sem comprometer a capacidade das gerações futuras de suprir suas próprias necessidades" (WCED, 1987, p. 43).

Após essa publicação, o cenário marcado pela preocupação com a escassez de recursos passou a fazer parte da inquietação de diversas instituições, como o Estado, as organizações e a sociedade (LEFF, 2010). Nesse aspecto, as organizações se destacaram, pois de acordo com Showm (2009) são as principais agentes, causadoras e solucionadoras, dos problemas ambientais e sociais, tanto no momento atual como no futuro.

Ao analisar uma organização que se diz sustentável ${ }^{1}$, ou declara que adota ações e processos sustentáveis, é possível identificar a abordagem de sustentabilidade adotada e o sentido dado ao processo decisório. Portanto, adotando-se as proposições teóricas presentes no Quadro 3, é possível refletir sobre quão distantes estão da combinação 3.3, por exemplo. Ou seja, encontrando a combinação adotada, encontram-se também orientações sobre 0 que vem sustentando o processo decisório. Possíveis incoerências devem ser discutidas e questionadas, pois a perspectiva teórico-conceitual que supostamente está direcionando o processo decisório, por vezes, pode não condizer com a prática cotidiana revelada nas narrativas dos gestores. Fazer esse tipo de análise mostra-se importante, já que existem diferentes abordagens e perspectivas adotadas pelos líderes organizacionais e, muitas vezes, o sentido atribuído ao processo decisório não consegue abarcar a complexidade que envolve as questões relacionadas à sustentabilidade e, com isso, constrangem os limites para que os mesmos caibam no atual nível de racionalidade já conhecido e praticado.

1. Adota-se como conceito de organização sustentável aquela que toma suas decisões fundamentando-se nos três pilares da sustentabilidade concomitantemente, considerando trade-offs e respeitando os horizontes temporais para cada pilar acontecer. A consideração das três dimensões da sustentabilidade foi proposta no nível empresarial primeiramente por John Elkington, em 1990, que relacionou os três pilares da sustentabilidade (social, econômico e ambiental), conhecidos na literatura como Triple Bottom Line - TBL. Originalmente utilizadas pelos profissionais da área financeira, a expressão bottom line traduz o resultado líquido de uma empresa; o termo TBL passou a definir a interação entre os resultados financeiros, ambientais e sociais, apresentando, portanto, uma nova forma de mensurar o desempenho organizacional (LEMME, 2010). 
Diante do exposto, este trabalho buscou problematizar, refletir e sugerir saídas para o seguinte problema: de que maneira as lógicas decisórias adotadas pelos gestores condicionam e delimitam os resultados de uma organização que almeja ser sustentável?

Nesse contexto, foram estudadas diferentes abordagens para a sustentabilidade (EGRI; PINFIELD, 1998; GLADWIN; KENNELLY; KRAUSE, 1995; KETOLA, 2009) que podem estar direcionando a visão de mundo dos líderes organizacionais. Essas abordagens combinam-se com diferentes lógicas decisórias que levam os líderes às escolhas que supostamente estariam relacionadas à sustentabilidade. Essas lógicas foram separadas por Garud e Gehman (2012) em três tipos: evolucionárias, relacionais e duracionais (temporais). A partir do framework proposto por Munck (2015), exposto no Quadro 3, serão ampliadas as reflexões ao explorar as possíveis implicações de cada combinação para a sustentabilidade nas organizações. Aqui se apresenta a principal contribuição deste artigo, responder a uma indagação original e permeada de consequências ignoradas pelos gestores, seja consciente ou inconscientemente. A "escolha", racional ou não, das abordagens e lógicas decisórias influenciam diretamente nos resultados de organizações que almejam ser sustentáveis, trazendo severas implicações às esferas ambientais, sociais e financeiras.

Os procedimentos metodológicos tiveram caráter qualitativo, pois se trata de um estudo que busca aprofundamento e interpretação, envolvendo um sistema complexo de significados a ser desvelado pelo pesquisador (TAKAHASHI, 2013). A pesquisa teórica triangulou teorias (sintetizadas nos Quadros 1 à 3), ideias e conceitos já existentes com o intuito de refinar fundamentos teóricos e propor novas concepções (DEMO, 2000). Nessas novas concepções é que residem as últimas, mas não menos importantes contribuições deste artigo. A partir das leituras realizadas, refinou-se as redações dos quadros, acrescentou-se explicações e inovou-se, criando o quarto quadro (Quadro 4), que sintetiza e trasnforma em narrativas as implicações da adoção das diversas combinações apresentadas no Quadro 3.

0 artigo foi estruturado em cinco seções: introdução; seguida pela evolução da sustentabilidade e seus paradigmas, em que são apresentadas as principais abordagens em relação à sustentabilidade (extremista econômica, extremista ambiental e integrativa); posteriormente foram trabalhadas as lógicas decisórias, nas quais são introduzidas três tipos de lógicas decisórias de acordo com Garud e Gehman (2012): evolucionárias, relacionais e duracionais (temporais); na quarta seção, foram apresentadas as implicações da lógica decisória nos objetivos para a busca da sustentabilidade; e, por fim, a última que trata das considerações finais, em que são discutidas as respostas para o objetivo proposto.

\section{EVOLUÇ̃̃O DA SUSTENTABILIDADE E SUAS ABORDAGENS: EXTREMISTA ECONÔMICA, EXTREMISTA AMBIENTAL E INTEGRATIVA}

A sustentabilidade pode ser compreendida a partir de diferentes visões de mundo, ou seja, com perspectivas paradigmáticas distintas, e, para compreender os desafios que envolvem a sustentabilidade nas organizações, é importante conhecer também os possíveis e diferentes paradigmas que a regem.

Sobre o uso de paradigmas no que se refere à sustentabilidade, Vos (2007) apresenta três divisões, nomeadas como: paradigma dominante, versão hard e versão soft. 0 
paradigma dominante, segundo o autor, visualiza a natureza apenas como uma fonte de recursos para a economia humana, portanto não considera a sustentabilidade em seus aspectos ambientais e sociais. Entende que a tecnologia pode resolver a maior parte dos problemas relacionados à natureza. Já as outras vertentes são céticas nesse sentido. 0 paradigma dominante não coloca limites nem em relação ao capital natural, nem ao crescimento econômico ou populacional. Já a chamada versão soft admite algum grau de substituição do capital natural, enquanto a versão hard não admite reduções. Sobre o crescimento econômico, as versões soft da sustentabilidade procuram reconciliar o crescimento econômico com a proteção ambiental. Elas demandam soluções do tipo "ganha-ganha". Já a versão hard defende uma redução ou inversão de crescimento. 0 crescimento populacional, na versão branda, deve ser acompanhado por compensações per capita. A versão hard, por sua vez, defende um retardo ou, mesmo, um declínio no crescimento. Sobre a equidade social, o paradigma dominante delega ao mercado, a versão soft volta-se para a área que esteja interferindo na proteção ecológica, enquanto a versão hard defende a ampla redistribuição de recursos.

Para Vos (2007), existem falhas em todos esses paradigmas e, por isso, o autor defende que não deve haver uma única definição para sustentabilidade; em vez disso, ela deve ser trabalhada e aperfeiçoada na prática, utilizando-se métricas para verificar seu progresso.

Já Gladwin, Kennelly e Krause (1995), Egri e Pinfield (1998) e Ketola (2009) defendem que existem alternativas em relação a paradigmas extremos voltados para a economia ou para o meio ambiente, oferecendo uma visão integrativa para tratar de sustentabilidade. A visão desses autores se faz atual, sendo corroborada por outros autores (BOELE; FABIG; WHELLER, 2001; PHILIPPE; BANSAL, 2013; WILLARD, 2014; MAIA; ZUCATO, 2015). Dyllick e Muff (2016) afirmam que ainda prevalece uma "grande desconexão" entre a sustentabilidade corporativa e a degradação ambiental, pois o entendimento sobre o que seja ser sustentável ainda é restrito e há uma incapacidade de integrar conhecimento de vários fluxos de literatura, incluindo micro e macro níveis de conhecimento. Ou seja, mesmo com a ampliação das práticas sustentáveis nas organizações, a degradação ambiental continua crescendo. Diante isso, buscando trazer soluções, são apresentadas proposições de integração de conhecimentos na sequência. Essas abordagens de Gladwin, Kennelly e Krause (1995), Egri e Pinfield (1998) e Ketola (2009) foram sintetizadas por Munck (2015) e estão presentes no Quadro 1.

É possível perceber que a perspectiva de Vos (2007) tem algumas aproximações com as de Egri e Pinfield (1998), que dividem as abordagens em paradigma social dominante, ambientalismo radical e ambientalismo renovado. 0 paradigma social dominante não difere do que explica Vos (2007), e o ambientalismo radical aproxima-se da versão hard, porém é muito mais rigoroso com as questões ambientais, defendendo o redesenho total dos sistemas agrícolas e industriais. Além disso, defende as éticas anticonsumistas e antimaterialistas. Já o ambientalismo renovado aproxima-se um pouco da versão soft de Vos (2007) e acredita na tecnologia para resolver os riscos ambientais, utilizando-se de conceitos da economia ecológica e industrial. 
Quadro 1 - Síntese de abordagens para o estudo da sustentabilidade

\begin{tabular}{|c|c|c|c|}
\hline Tecnocentrismo & Ecocentrismo & Sustaincentrismo & \\
\hline $\begin{array}{l}\text { Suas origens remetem à Revo- } \\
\text { lução Científica do século XVII. } \\
\text { Com o liberalismo, iniciou-se a } \\
\text { tendência de privilegiar os seres } \\
\text { humanos frente à natureza. } \\
\text { Com a evolução tecnológica, } \\
\text { resolver-se-iam todos os } \\
\text { problemas. Representa o pen- } \\
\text { samento dominante, pois suas } \\
\text { proposições são mais alinhadas } \\
\text { aos preceitos econômicos e aos } \\
\text { atuais modelos de gestão. }\end{array}$ & $\begin{array}{l}\text { Proveniente de uma filosofia } \\
\text { que apregoa um estilo de vida } \\
\text { que se conforma com a ordem } \\
\text { da natureza, com a reverência } \\
\text { ao planeta, alinha-se com os } \\
\text { movimentos transcendentalistas } \\
\text { e preservacionistas. Esta aborda- } \\
\text { gem é marcada por uma ecologia } \\
\text { profunda, a qual rejeita qualquer } \\
\text { dominação humana sobre a } \\
\text { natureza. }\end{array}$ & $\begin{array}{l}\text { Representa um paradigma in- } \\
\text { teressado em compreender o } \\
\text { desenvolvimento sustentável } \\
\text { como um esforço dialético. } \\
\text { Busca articular uma visão de } \\
\text { mundo centrada na busca } \\
\text { por uma reconciliação entre } \\
\text { posições científicas radicais. } \\
\text { É um paradigma ainda } \\
\text { embrionário em dias atuais, } \\
\text { mesmo tendo sido descrito } \\
\text { em } 1995 \text {. }\end{array}$ & $\begin{array}{l} \\
\text { Gladwin, } \\
\text { Kennelly } \\
\text { e Krause } \\
\text { (1995) }\end{array}$ \\
\hline Paradigma Social Dominante & Ambientalismo Radical & Ambientalismo Renovado & \\
\hline $\begin{array}{l}\text { Representa a aderência aos } \\
\text { princípios e objetivos econômi- } \\
\text { cos neoclássicos (crescimento } \\
\text { econômico e lucro). Os fatores } \\
\text { naturais são tratados como } \\
\text { externalidades ou recursos } \\
\text { infinitos. A resolução de "pos- } \\
\text { síveis" problemas ambientais } \\
\text { acontecerá por meio do progres- } \\
\text { so científico. }\end{array}$ & $\begin{array}{l}\text { Critica a comunidade científica } \\
\text { e industrial e promove uma } \\
\text { visão da biosfera e da sociedade } \\
\text { baseada em princípios ecológicos } \\
\text { do holismo, do equilíbrio da } \\
\text { natureza, da diversidade, dos } \\
\text { limites finitos e das mudanças } \\
\text { dinâmicas. Defende o redesenho } \\
\text { total dos sistemas agrícola e } \\
\text { industrial. Reforça as éticas anti- } \\
\text { consumistas/anti-materialistas. }\end{array}$ & $\begin{array}{l}\text { Sugere modificações nos } \\
\text { valores antropocêntricos } \\
\text { a fim de incluir valores } \\
\text { biocêntricos. Por meio } \\
\text { da tecnologia, tem-se o } \\
\text { progresso científico e econô- } \\
\text { mico, bem como os meios } \\
\text { para a gerência dos riscos } \\
\text { ambientais. Usa conceitos } \\
\text { da economia ecológica e } \\
\text { ecologia industrial. }\end{array}$ & $\begin{array}{l}\text { Egri e } \\
\text { Pinfield } \\
\text { (1998) }\end{array}$ \\
\hline Paradigma Modernista & Paradigma Pós-Modernista & & \\
\hline $\begin{array}{l}\text { Visão racionalizada do } \\
\text { indivíduo; preza por relações } \\
\text { estratégicas de custo-benefício. }\end{array}$ & \multirow{5}{*}{$\begin{array}{l}\text { Trata das interações intra e } \\
\text { entre ecossistemas. No cenário } \\
\text { empresarial, a sobrevivência } \\
\text { ou não de uma empresa irá } \\
\text { depender do ambiente com- } \\
\text { petitivo, da sociedade e do } \\
\text { ecossistema natural. Um conceito } \\
\text { insosso adotado com vistas a } \\
\text { evitar a controvérsia entre duas } \\
\text { visões de mundo conflitantes: } \\
\text { desenvolvimento sustentável (DS) } \\
\text { versus crescimento sustentável } \\
\text { (CS). O papel das empresas é } \\
\text { alcançar meios de subsistência } \\
\text { sustentáveis, porém a população } \\
\text { pobre acaba por ficar dependente } \\
\text { e subordinada a tais empresas. } \\
\text { Multinacionais tendem a agir em } \\
\text { oposição aos bons cidadãos - } \\
\text { reflexos do individualismo. }\end{array}$} & \multirow{5}{*}{$\begin{array}{l}\text { Tem como finalidade sen- } \\
\text { sibilizar sobre os efeitos do } \\
\text { lado inconsciente do com- } \\
\text { portamento humano. Busca } \\
\text { demonstrar que, no fundo, } \\
\text { todos os seres humanos } \\
\text { possuem os mesmos valores. } \\
\text { Desde a última década, } \\
\text { alguns sinais ainda fracos } \\
\text { mostram-se formadores deste } \\
\text { novo paradigma. }\end{array}$} & \multirow{5}{*}{$\begin{array}{l}\text { Ketola } \\
\text { (2009) }\end{array}$} \\
\hline $\begin{array}{l}\text { No âmbito empresarial, esta } \\
\text { visão determina as responsa- } \\
\text { bilidades sociais e ambientais } \\
\text { adotadas. }\end{array}$ & & & \\
\hline $\begin{array}{l}\text { Objetivos financeiros têm } \\
\text { prioridade sobre questões } \\
\text { socioambientais. }\end{array}$ & & & \\
\hline $\begin{array}{l}\text { Utilitarismo: uma postura } \\
\text { mais moderada do egoísmo } \\
\text { empresarial, porém, na prática, } \\
\text { tende a beneficiar grupos mais } \\
\text { poderosos. }\end{array}$ & & & \\
\hline $\begin{array}{l}\text { Responsabilidades são } \\
\text { assumidas somente se gerarem } \\
\text { benefícios }\end{array}$ & & & \\
\hline
\end{tabular}

Fonte: Extraído de Munck (2015).

Em outro tipo de abordagem, Ketola (2009) traz uma alternativa aos paradigmas modernos e pós-modernos de sustentabilidade empresarial, defendendo um novo paradigma, o pré-morfeanista. Para a autora, enquanto o modernismo explora os seres humanos e a natureza, o pós-modernismo apenas analisa e acaba seguindo os padrões naturais. O novo paradigma proposto, pré-morfeanista, sensibiliza-se para os efeitos do lado inconsciente do 
comportamento humano, mostrando que, no fundo, toda a humanidade tem os mesmos valores. A aprendizagem humana é coletiva, porém, em um processo muito lento, porque as pessoas tentam reprimir a memória coletiva quando contradizem sua própria satisfação e necessidade imediata.

O estudo trazido por Gladwin, Kennelly e Krause (1995) avalia o paradigma convencional do tecnocentrismo e seu oposto, conhecido como ecocentrismo, e defende que nenhum dos dois sozinhos é suficiente para alcançar o desenvolvimento sustentável. Os autores propõem o estudo, então, de um novo paradigma, o sustaincentrism. Esse novo paradigma sugere que as teorias de gestão devem ser vistas como um mundo relativamente completo, em vez de vazio, buscando fazer uma reconciliação entre posições científicas radicais.

O tecnocentrismo, segundo os autores, é caracterizado por individualismo, modos reducionistas e positivistas de raciocínio. A humanidade é vista como separada e superior à natureza. 0 mundo natural é visto apenas como um valor monetário, assim como uma mercadoria da qual os seres humanos podem tirar benefícios. Segundo Gladwin, Kennelly e Krause (1995) esse tipo de pensamento é egoísta, linear, instrumental e racional. Acredita-se, nesse pensamento, que os recursos físicos do Planeta Terra são inesgotáveis por conta da capacidade humana em conseguir substitui-los por meio da tecnologia.

O ecocentrismo, por sua vez, de acordo com Gladwin, Kennelly e Krause (1995), apesar de conter verdades nas esferas físicas e ecológicas, possui falhas ontológicas ao acreditar que o ser humano é inferior à natureza. Para os autores, a sustentabilidade ecológica não pode ser alcançada em condições de insustentabilidade social ou econômica. O ecocentrismo falha no aspecto social, visto que possui pouca orientação sobre a terrível expansão da pobreza, do abuso aos direitos humanos, das desigualdades de renda e outras patologias sociais que se perpetuam pelo mundo industrial; não garantindo meios de sobrevivência sustentáveis.

De acordo com essa proposta de Gladwin, Kennely e Krause (1995) é possível perceber que o ecocentrismo não consegue abarcar a sustentabilidade em seu aspecto social e o tecnocentrismo subestima a importância do mundo natural, não respeitando o fato de que este possui recursos indispensáveis à sobrevivência no Planeta, que não podem simplesmente ser substituídos por meio da tecnologia. É justamente nessa perspectiva integradora que os autores se baseiam para propor o paradigma sustaincentrism (GLADWIN; KENNELLY; KRAUSE, 1995).

No paradigma sustaincentrism a humanidade deve conduzir melhor a Terra, estabilizando o tamanho da população mediante a participação global e a equidade das mulheres no desenvolvimento, reduzindo o consumo em países desenvolvidos. Devem ser exigidas normas de segurança para minimizar as perdas irreversíveis de recursos renováveis. As tecnologias devem, ainda, ser adotadas de forma consciente, com justiça e responsabilidade, realizando estudos rigorosos sob o impacto ecológico, social e econômico antes de introduzir novas tecnologias. Defende-se ainda que é importante considerar partes do capital natural como insubstituíveis, como por exemplo, a diversidade genética, a biodiversidade de algumas espécies e a camada de ozônio. 
Em relação aos paradigmas já citados, Philippe e Bansal (2013) defendem que as organizações que adotam a sustentabilidade soft apenas trazem as preocupações ambientais para dentro da estrutura já existente, enquanto a sustentabilidade hard procura mudar a estrutura e o processo decisório integrando à empresa em sistemas ecológicos ambientais ou sociais. O paradigma soft da sustentabilidade pode ser caracterizado por descontinuidades espaço-temporais, já o paradigma hard da sustentabilidade incorpora conexões temporais e espaciais.

Dentro desse contexto, conhecer as lógicas decisórias parece fundamental, já que são elas as norteadoras do processo decisório. Diante disso, a próxima seção tem como intuito compreender as lógicas decisórias para posteriormente identificar as possíveis implicações de escolhas em busca da sustentabilidade nas organizações.

\section{LÓGICAS DECISÓRIAS E SUSTENTABILIDADE NAS ORGANIZAÇÕES}

O entendimento da lógica decisória adotada pelos gestores em relação à sustentabilidade é importante, pois há lacunas nos estudos sobre a tomada de decisão rumo à sustentabilidade nas organizações. São raros os entendimentos plausíveis por parte dos estudiosos e praticantes sobre o sentido do processo decisório que busca inter-relacionar as exigências e objetivos econômicos, ambientais e sociais. Tendo em vista os primeiros resultados com a prática da sustentabilidade nas organizações, tanto estudiosos quanto gestores estão percebendo e compreendendo as consequências negativas de se tomar decisões sob a tutela de incoerentes, insuficientes, inconsistentes e descontextualizados conceitos sobre 0 que é ser sustentável em contexto organizacional (MUNCK, 2013).

Essas incoerências e a falta de conexões na tomada de decisão acontecem quando os gestores colocam sua atenção apenas no curto prazo, pois, conforme atesta Munck (2013), as decisões estão fundamentadas no presente, mas envolvem muitas comparações, análises contextuais, interesses paradoxais e contrastes em termos de passado e futuro que impactam diretamente as escolhas feitas pelos gestores. Fato corroborado por Landrum (2017), pois este afirma que os modelos de gestão devem superar três críticas: (1) consideração de modelos econômicos que incorporem os limites naturais, reconheçam os limites ao crescimento, à produção e ao consumo e uso de recursos; (2) inserção em suas estratégias de elementos de redistribuição de riqueza, de recursos e de poder; e (3) ajuda na revisão de medidas de sucesso para além do PIB e medidas de curto prazo.

Dentro desse contexto, Garud e Gehman (2012) explicam a existência de três tipos de perspectivas decisórias: evolucionárias, relacionais e duracionais (temporais). A perspectiva evolucionária é dependente de trajetória em uma visão restrita de agência; o caminho estabelecido é determinado pelas condições iniciais e contingências externas e pelos investimentos que já foram realizados em tecnologias, sendo que as novas soluções (inclusive referentes à sustentabilidade) só acontecem por acaso. Já a perspectiva relacional, em vez de considerar ambientes de seleção como dados, diminui as diferenças entre agência e estrutura, micro e macro, adotando uma ontologia relacional. Nesse caso, os atores não são nem de dentro, nem de fora, mas acompanham os eventos em curso. "Como resultado, 'quem somos' e 'o que sabemos' são determinados pelas múltiplas constantes mudanças de redes de atores em que estamos implicados" (GARUD; GEHMAN, 2012, p. 983). Diante 
disso, muitos estudiosos (GEELS, 2010; GENUS; COLES, 2008; SHOVE; WALKER, 2010) têm dado importância para os benefícios em se adotar a perspectiva relacional quando se trata de sustentabilidade, especificamente pelo entendimento mútuo entre atores sociais, fazendo surgir o significado que se transpõe na prática.

Enquanto a perspectiva duracional (temporal) vai além das mudanças nos ambientes de seleção e reconfiguração das redes de associações, também é intertemporal em sua própria definição: "[...] satisfazer as necessidades da geração presente sem comprometer a capacidade das gerações futuras satisfazerem as suas necessidades" (WCED, 1987, p. 43). Conforme atestam Garud e Gehman (2012, p. 985), existem tensões que fazem parte de qualquer percurso da sustentabilidade, buscando adaptar e conciliar as "necessidades do presente" com as "necessidades do futuro". "As jornadas de sustentabilidade estão repletas de armadilhas locais, racionalidade, inconsistências dinâmicas, assincronias e preferências que se desenvolvem" (GARUD; GEHMAN, 2012, p. 985). Os autores destacam que a perspectiva temporal de ontologia narrativa propõe que não se limite a capacidade de agência apenas por símbolos culturais, mas mediante projetos pessoais em constante evolução que são criados em nossas memórias do passado, as antecipações do futuro e atenção no presente (GARUD; GEHMAN, 2012) Ainda sobre esses três tipos de lógicas decisórias, Munck (2015) as sintetizou e completou conforme o Quadro 2.

Em uma perspectiva intertemporal, o passado não é necessariamente algo a ser deixado para trás ou visto como um impedimento que deve ser rompido em busca do futuro; por outro lado, é a própria estrutura e base para as ações. Com isso, as jornadas para um futuro sustentável podem implicar voltar às práticas que foram arquivadas, abandonadas ou, mesmo, estigmatizadas como erros (GARUD; GEHMAN, 2012).

Quadro 2 - Síntese das perspectivas decisórias capazes de orientar a gestão da sustentabilidade nas organizações

\begin{tabular}{|l|}
\hline Perspectiva Evolucionária \\
\hline Teóricos como Vergne e Durand (2010) descrevem os processos decisórios a partir da ideia de \\
dependência de trajetória (Path Dependence). O caminho adotado é determinado pelas con- \\
dições iniciais e contingências exógenas. Os eventos desempenham um papel fundamental e \\
são, na maior parte das vezes, vistos como os iniciadores de decisões subsequentes. Decisões \\
sobre investimentos, por exemplo, progridem em acordo e em dependência de investimentos \\
anteriores e não permitem ou não consideram uma volta a zero. A trajetória assumida ser- \\
ve como constrangimento e ameaça ao raciocínio que dela diverge. Soluções inovadoras que \\
atendam às premissas da sustentabilidade, por exemplo, só poderiam surgir por acaso e, \\
mesmo assim, se não comprometessem ou interrompessem as operações em curso. Ou seja, \\
as trajetórias seriam produzidas a partir do sentido revigorado pelas narrativas dos gestores. \\
Reforçam assim, o caminho escolhido, como o único que faz sentido. Anderson e Tushman \\
(1990) corroboram o perigo em haver sentidos únicos ao alertarem para a situação de conflito, \\
demarcada pela luta pela funcionalidade, que emerge quando agentes decidem apostar em \\
diferentes tecnologias que se chocam com as crenças sobre a trajetória assumida. Eventual- \\
mente, uma nova trajetória prevaleceria sobre as atuais, mas seria natural enclausurar um novo \\
projeto como a sustentabilidade até que sua era ou seu tempo de mudança incremental sirva à \\
manutenção do status quo. Segundo Meyer, Gaba e Colwell (2005), uma nova era de eficiên- \\
cia e confiabilidade somente viria e quebraria o atual sentido a partir de choques externos e \\
interrupções capazes de desenclausurar os participantes do estado assumido como verdadeiro. \\
\hline
\end{tabular}




\begin{abstract}
Perspectiva Relacional
Enquanto na perspectiva evolucionária considera-se os agentes como dependentes de eventos anteriores, o ambiente externo como determinado e os critérios para alcance de sucesso como inconfundíveis, a perspectiva relacional chama a atenção para as muitas maneiras em que as decisões de agência estão distribuídas. A seleção de ambientes pode ser moldada, sistemas de avaliação e critérios de sucesso são tidos como passíveis de equívocos. Os agentes passam a ser considerados em redes de atores em esforços mútuos para moldar as instituições. 0 'mercado' não é mais uma seleção pontual do ambiente, mas um importante campo de disputas por significados onde os critérios sobre o que conta, como se conta e para quem conta, são pelos próprios atores moldados. Carlile (2004) ressalta que a perspectiva relacional chama a atenção para questões diferentes e permite distintos insights. Uma transição para a sustentabilidade em contexto organizacional nessa perspectiva não seria uma questão de passar de um modelo de desenvolvimento para outro, mas, sim, continuamente, negociar a realização de acordos humanos sobre novos elementos envolvendo desvios e contestações. Este é um processo de criação de caminhos e não de dependência de caminhos assumidos (GARUD; GEHMAN; KURAMASWAMY, 2011) Múltiplos atores (consumidores, produtores, reguladores, formuladores de políticas públicas etc.) unidos a expectativas coletivas, na forma de redes formais e associações, estarão inerentemente envolvidos de diferentes formas e assumindo diferentes papéis, muitas vezes conflitantes, em busca da sustentabilidade. Segundo Geels (2010), a capacidade de agir dos envolvidos será então moldada pelas redes de atores. Se pensarmos nos objetivos da sustentabilidade essa seria uma perspectiva mais capaz de viabilizá-los.

\section{Perspectiva Temporal}

Às duas perspectivas - evolucionária e relacional - é possível adicionar outra dimensão quando se discute sustentabilidade nos negócios. Em lugar de perceber o processo decisório dependente de trajetórias assumidas que se retroalimentam, ou como criador de trajetórias, ele também pode ser percebido a partir de condições iniciais não dadas, mutantes e criadoras de mecanismos que surgem a partir de si mesmos. Além disso, nessa perspectiva, os atores não estão necessariamente fechados em si mesmos à espera de pressões externas para se abrirem. Segundo Brown e Eisenhardt (1997), dado que os diferentes atores interdependentes podem ver seus passados diferentemente, eles podem ter diferentes projeções do futuro que se desdobram em seus próprios interesses compartilhados. Ao pensar e agir numa perspectiva temporal, os gestores teriam que definir o que entendem por curto, médio e longo prazos, bem como sobre o que entendem por passado, presente e futuro. A partir daí, poderiam discutir com convicção sobre posicionamentos frente aos trade-offs gerados ao se considerar os três pilares da sustentabilidade em diferentes escalas temporais. Por exemplo, as questões ambientais podem se estender em escalas de tempo geológicas que envolvem centenas de anos, já as questões sociais estariam mais restritas ao 'tempo' de uma geração. Já o tempo econômico, dependerá do entendimento do que seja curto, médio ou longo prazos para a realização do lucro. Portanto, considerar estes elementos na gestão da sustentabilidade em contexto organizacional, exigiria um novo sentido, amplo e capaz de integrar as particulares dimensões do tempo inerentes aos pilares da sustentabilidade no processo decisório.
\end{abstract}

Fonte: Sintetizado por Munck (2015) com base em Garud e Gehman (2012),

Gao e Bansal (2013), Bansal e Desjardine (2014).

Dentro desse contexto, a próxima seção tem como intuito compreender como determinadas lógicas decisórias podem influenciar na busca da sustentabilidade nas organizações, buscando trazer as possíveis implicações dessas escolhas.

\title{
IMPLICAÇÕES DA LÓGICA DECISÓRIA NOS OBJETIVOS EM BUSCA DA SUSTENTABILIDADE
}

No intuito de compreender como as escolhas de certas abordagens e lógicas decisórias influenciam nos resultados da sustentabilidade nas organizações, em um primeiro momento foi realizada uma análise do framework (Quadro 3). 
Quadro 3 - Framework descritivo das possíveis narrativas em curso que podem estar subsidiando o processo decisório em prol da sustentabilidade

\begin{tabular}{|c|c|c|c|}
\hline \multicolumn{4}{|c|}{ Abordagens para a sustentabilidade nas organizações } \\
\hline $\begin{array}{c}\text { Perspectivas } \\
\text { Decisórias para a } \\
\text { Sustentabilidade }\end{array}$ & 1. Extremista Econômica & 2. Extremista Ambiental & 3. Integrativa \\
\hline 1. Evolucionária & $\begin{array}{l}\text { Decisões que reforçam } \\
\text { a priorização de lucros } \\
\text { em função de decisões } \\
\text { econômicas prévias de } \\
\text { curto prazo }\end{array}$ & $\begin{array}{c}\text { Decisões que reforçam a } \\
\text { priorização da preservação } \\
\text { ambiental em função de } \\
\text { decisões prévias de curto } \\
\text { prazo }\end{array}$ & $\begin{array}{l}\text { Decisões que consideram os } \\
\text { três pilares, mas ainda numa } \\
\text { perspectiva de curto/médio } \\
\text { prazo dependente de decisões } \\
\text { anteriores }\end{array}$ \\
\hline 2. Relacional & $\begin{array}{l}\text { Decisões que observam } \\
\text { relações entre os pilares, } \\
\text { mas ainda considerando } \\
\text { perspectivas econômicas } \\
\text { internas de curto/médio } \\
\text { prazo }\end{array}$ & $\begin{array}{l}\text { Decisões que observam } \\
\text { relações entre os pilares, } \\
\text { mas ainda considerando } \\
\text { perspectivas ambientais de } \\
\text { curto/médio prazo }\end{array}$ & $\begin{array}{c}\text { Decisões que consideram os } \\
\text { três pilares, suas inter-relações, } \\
\text { mas ainda sem considerar } \\
\text { implicações (trade-offs) espaço- } \\
\text {-temporais }\end{array}$ \\
\hline 3.Temporal & $\begin{array}{l}\text { Decisões que observam } \\
\text { as narrativas em curso } \\
\text { considerando perspectivas } \\
\text { externas de médio/longo } \\
\text { prazo, mas priorizando } \\
\text { aspectos econômicos }\end{array}$ & $\begin{array}{l}\text { Decisões que observam } \\
\text { as narrativas em curso } \\
\text { considerando perspectivas } \\
\text { externas de médio/longo } \\
\text { prazo, mas priorizando } \\
\text { aspectos ambientais }\end{array}$ & $\begin{array}{c}\text { Decisões que consideram os } \\
\text { três pilares da sustentabilidade } \\
\text { em diferentes escalas de tempo, } \\
\text { numa perspectiva de longo } \\
\text { prazo e com reflexões profundas } \\
\text { sobre trade-offs e sentidos a } \\
\text { partir das narrativas em curso }\end{array}$ \\
\hline
\end{tabular}

Fonte: Adaptado de Munck (2015).

Ao framework elaborado por Munck (2015) foram acrescidos números às classificações no intuito de facilitar a descrição das possíveis combinações entre as abordagens e perspectivas decisórias assumidas pela gestão da sustentabilidade nas organizações. Com base nesse framework e nos constructos de Gladwin, Kennelly e Krause (1995), Egri e Pinfield (1998) e Ketola (2009) apresentados nos Quadros 1 e 2, com Garud e Gehman (2012), Gao e Bansal (2013), Bansal e Desjardine (2014) e complementos dos demais autores estudados, foi possível elaborar o Quadro 4, em que os autores deste trabalho propõem combinações analisando o framework presente no Quadro 3, combinando cada tipo de perspectiva decisória (evolucionária, relacional e temporal) com cada tipo de abordagem para sustentabilidade nas organizações (extremista econômica, extremista ambiental e integrativa). A partir disso, foi possível ter um ponto de partida para identificar e analisar as possíveis implicações que se têm ao adotar determinadas abordagens, combinadas com determinadas perspectivas decisórias. 
Quadro 4 - Combinação entre Abordagens e Perspectivas decisórias e suas possíveis implicações para as organizações

\begin{tabular}{|c|c|}
\hline $\begin{array}{l}\text { Combinação entre abordagens e } \\
\text { perspectivas decisórias }\end{array}$ & Implicações no que diz respeito à busca da sustentabilidade \\
\hline $\begin{array}{l}1.1 \text { Econômica-evolucionária: Em uma } \\
\text { combinação desse tipo, reforçam-se as } \\
\text { decisões tomadas anteriormente, sem co- } \\
\text { gitar uma mudança de sentido. Com isso, } \\
\text { as decisões focadas apenas em lucro, } \\
\text { como no caso das abordagens extremistas } \\
\text { econômicas, não seriam questionadas, } \\
\text { apenas se reforçaria a ideia de buscar o } \\
\text { lucro em detrimento de outros interesses } \\
\text { e voltando-se para o curto prazo. }\end{array}$ & $\begin{array}{l}\text { Esse tipo de combinação não pode, sequer, ser considerada } \\
\text { uma orientação para a sustentabilidade, já que estaria } \\
\text { voltada ao curto prazo e apenas a um dos pilares, no caso, } \\
\text { o econômico. Uma organização com esse tipo de orientação } \\
\text { pode trazer sérios danos ao meio ambiente e à sociedade. } \\
\text { Não questionando os seus meios de produção nem as } \\
\text { externalidades causadas por seus detritos, esse é o tipo de } \\
\text { empresa que pode trazer sérios desastres ambientais ou } \\
\text { acidentes vitimando pessoas, já que, ao tomar uma decisão } \\
\text { apenas pensando no lucro, pode não prever os riscos de } \\
\text { suas ações ou até mesmo correr o risco por considerar que } \\
\text { pode tirar uma vantagem econômica muito maior. Esse tipo } \\
\text { de empresa somente adotaria a sustentabilidade de maneira } \\
\text { superficial, buscando tirar proveito da imagem que ser } \\
\text { sustentável pode trazer, porém esse tipo de orientação não se } \\
\text { sustenta em longo prazo. }\end{array}$ \\
\hline $\begin{array}{l}1.2 \text { Econômica-relacional: Ao considerar } \\
\text { a perspectiva relacional, essa abordagem } \\
\text { econômica leva em conta os outros } \\
\text { pilares, porém priorizando os ganhos } \\
\text { financeiros de curto e médio prazos. }\end{array}$ & $\begin{array}{l}\text { Isso significa que, em uma análise de trade-offs, os pilares } \\
\text { ambientais e sociais estariam sempre em segundo plano. } \\
\text { O econômico ainda prevalece, com isso não suportaria } \\
\text { decisões que exigissem um prazo maior para trazer retornos } \\
\text { financeiros. Esse tipo de combinação não consegue trazer } \\
\text { grandes avanços no que diz respeito à sustentabilidade em } \\
\text { uma organização, porém pode trazer menos riscos do que a } \\
\text { primeira combinação, pois, ainda que priorize o econômico, } \\
\text { leva em conta as consequências para o meio ambiente e a } \\
\text { sociedade. }\end{array}$ \\
\hline $\begin{array}{l}\text { 1.3 Econômica-temporal: Considerando } \\
\text { a perspectiva temporal, analisa as nar- } \\
\text { rativas em curso, avaliando as decisões } \\
\text { considerando o médio e o longo prazos, } \\
\text { porém irá reforçar as decisões que priori- } \\
\text { zem o econômico. }\end{array}$ & $\begin{array}{l}\text { Esse tipo de combinação é pouco provável, já que normal- } \\
\text { mente uma organização que leva em conta as questões } \\
\text { temporais e espaciais não fica pautada apenas no âmbito } \\
\text { econômico. Porém, ao considerar essa possibilidade, enten- } \\
\text { de-se que essa combinação leve em conta as consequências } \\
\text { que suas decisões podem trazer em longo prazo, evitando, } \\
\text { assim, maiores riscos e danos à sociedade, incluindo danos } \\
\text { às gerações futuras. No entanto, poderia haver melhores } \\
\text { avanços para a sustentabilidade se, ao considerar trade-offs, } \\
\text { não se priorizasse sempre o econômico. }\end{array}$ \\
\hline $\begin{array}{l}2.1 \text { Ambiental-evolucionária: Essa } \\
\text { combinação reforça as decisões anterio- } \\
\text { res, priorizando a preservação ambiental, } \\
\text { e não leva em conta os outros pilares. }\end{array}$ & $\begin{array}{l}\text { Esse tipo de combinação está preocupada apenas com } \\
\text { questões ecológicas, não levando em conta os outros pilares, } \\
\text { especialmente não se preocupando com problemas relacio- } \\
\text { nados ao social (pobreza, miséria, qualidade de vida). Não é } \\
\text { um tipo de combinação que pode servir de orientação para a } \\
\text { sustentabilidade. }\end{array}$ \\
\hline $\begin{array}{l}2.2 \text { Ambiental-relacional: Essa com- } \\
\text { binação leva em conta outros pilares, } \\
\text { porém, em uma perspectiva de curto e } \\
\text { médio prazos e voltando-se a priorizar o } \\
\text { ambiental. }\end{array}$ & $\begin{array}{l}\text { Combinações desse tipo, apesar de avaliar os outros pilares, } \\
\text { ainda estão muito preocupadas em resolver as questões } \\
\text { ambientais e, com isso, em uma avaliação de trade-offs, } \\
\text { os investimentos estariam voltados para resolver problemas } \\
\text { ambientais prioritariamente, sacrificando, na maioria das } \\
\text { vezes, as questões sociais. }\end{array}$ \\
\hline $\begin{array}{l}\text { 2.3 Ambiental-temporal: Essa combi- } \\
\text { nação considera a dimensão temporal, } \\
\text { avaliando as consequências de decisões } \\
\text { em longo prazo, todavia priorizando o } \\
\text { ambiental. }\end{array}$ & $\begin{array}{l}\text { Esse tipo de combinação pode trazer avaliações importantes } \\
\text { sobre as consequências que as ações humanas podem trazer } \\
\text { para o meio ambiente em longo prazo. Porém, como prioriza } \\
\text { o ambiental, não consegue avançar para uma orientação de } \\
\text { sustentabilidade sistêmica, avaliando e considerando também } \\
\text { as dimensões econômicas e sociais. }\end{array}$ \\
\hline
\end{tabular}




\begin{tabular}{|c|c|}
\hline $\begin{array}{l}\text { Combinação entre abordagens e } \\
\text { perspectivas decisórias }\end{array}$ & Implicações no que diz respeito à busca da sustentabilidade \\
\hline $\begin{array}{l}3.1 \text { Integrativa-evolucionária: Essa } \\
\text { combinação, apesar de considerar os } \\
\text { três pilares, ainda toma as decisões } \\
\text { dependendo da trajetória assumida } \\
\text { anteriormente e está voltada ao curto e ao } \\
\text { médio prazos. }\end{array}$ & $\begin{array}{l}\text { Esse tipo de combinação pode trazer alguns avanços na } \\
\text { busca da sustentabilidade, já que, ao tomar decisões, avalia } \\
\text { as consequências para os três pilares, porém não consegue } \\
\text { avançar muito, pois está preso nas decisões assumidas } \\
\text { anteriormente. Não existe uma mudança de sentido quando } \\
\text { necessário. }\end{array}$ \\
\hline $\begin{array}{l}3.2 \text { Integrativa-relacional: Essa com- } \\
\text { binação considera os três pilares, suas } \\
\text { inter-relações, porém ainda não existe } \\
\text { uma preocupação com as consequências } \\
\text { espaço-temporais. }\end{array}$ & $\begin{array}{l}\text { É uma combinação que pode trazer grandes avanços em } \\
\text { relação à busca da sustentabilidade, já que existe uma } \\
\text { articulação entre vários atores (consumidores, produtores, } \\
\text { reguladores, responsáveis por políticas públicas etc.). Aqui } \\
\text { não estão mais dependentes de decisões assumidas, mas } \\
\text { criam novos caminhos e estratégias de maneira coletiva, por } \\
\text { meio de redes formais e associações, assumindo distintos } \\
\text { papéis, algumas vezes conflitantes, mas com o mesmo intuito } \\
\text { de buscar a sustentabilidade. Um exemplo disso são grandes } \\
\text { corporações que, na busca da sustentabilidade, fazem alian- } \\
\text { ças com ONGs voltadas para questões ambientais e sociais. } \\
\text { Esse tipo de associação não era sequer cogitada anos atrás. } \\
\text { Essa combinação conta com uma rede de atores envolvida } \\
\text { na busca da sustentabilidade, enriquecendo o processo e } \\
\text { trazendo grandes avanços para toda a sociedade. }\end{array}$ \\
\hline $\begin{array}{l}3.3 \text { Integrativa-temporal: Esse tipo de } \\
\text { combinação, além de considerar os três } \\
\text { pilares da sustentabilidade, considera-os } \\
\text { em diferentes escalas de tempo, levando } \\
\text { em conta o longo prazo, e avalia os trade- } \\
\text {-offs a partir das narrativas, avaliando a } \\
\text { possibilidade de mudança de sentido. }\end{array}$ & $\begin{array}{l}\text { Acredita-se que este seja o tipo ideal de combinação } \\
\text { entre abordagem integrativa e perspectiva temporal, já } \\
\text { que consegue abarcar questões complexas relacionadas a } \\
\text { trade-offs (ambiental, econômico e social), fazendo uma } \\
\text { análise de cada um em diferentes escalas de tempo e espaço. } \\
\text { Uma empresa que adota esse tipo de lógica decisória não } \\
\text { se limita a cumprir apenas a legislação, está procurando ir } \\
\text { além, fazendo parcerias e cobrando de seus stakeholders } \\
\text { uma postura consciente e alinhada com os princípios da } \\
\text { sustentabilidade. Uma empresa desse tipo deixa de fazer um } \\
\text { negócio, mesmo que seja rentável em curto prazo, se esse } \\
\text { for trazer prejuízos ambientais ou sociais em curto e médio } \\
\text { ou longo prazos. Por isso, acredita-se que esse tipo de com- } \\
\text { binação seria ideal quando se pensa em tomada de decisão } \\
\text { relacionada à sustentabilidade em nas organizações. }\end{array}$ \\
\hline
\end{tabular}

Fonte: Sarábia-Cavenaghi (2016) construido com base nos Quadros 1, 2 e 3 e demais autores estudados.

A partir da análise dessas combinações, acreditamos que a abordagem integrativa, comparada às demais, mostra-se mais evoluída, independente da perspectiva, pois considera todos os pilares ao tomar decisões. Porém, a abordagem integrativa, quando combinada com a perspectiva temporal, consegue ter avanços ainda mais relevantes do que quando combinada a uma perspectiva evolucionária, que ainda é dependente das decisões tomadas anteriormente ou mesmo à perspectiva relacional que, apesar de admitir criar novos caminhos ao tomar decisões, ainda não consegue abarcar a dimensão espaço-temporal. Já a abordagem integrativa, voltada à perspectiva temporal, olha para os três pilares, considerando cada um em uma escala de tempo pertinente, e engloba todos eles em uma perspectiva de longo prazo. Esta reflete profundamente sobre os problemas relacionados à sustentabilidade a partir de trade-offs, utilizando-se do sentido propagado por meio da análise de narrativas. 
Ao fazer essa relação entre as abordagens e perspectivas decisórias para a sustentabilidade nas organizações, é possível perceber que existem muitas maneiras de se pensar e agir em relação à sustentabilidade. Este trabalho parte do pressuposto de que a escolha dessas abordagens e perspectivas nas organizações trará implicações positivas ou negativas relacionadas aos objetivos da sustentabilidade. Nesse sentido, sugere-se considerar a sustentabilidade como um conceito intertemporal, em exercício de atuação, fixada no presente, mas com diversas implicações e interesses contrastantes e paradoxais que envolvem passado e futuro. Fortalecem-se as exigências em se adotar nas organizações abordagens decisórias mais robustas que as causais, evolutivas e instrumentais.

Munck (2015) atesta que muitas organizações estão psiquicamente presas, buscando apenas ganhos financeiros a curto prazo, com investimentos fortuitos e oportunistas nas áreas socioambientais. As decisões organizacionais que se atêm apenas aos lucros acabam gerando ou até mesmo agravando os problemas ambientais (MAIA; PIRES, 2011).

A sociedade está cada vez mais exigente com as empresas e clama para que estas assumam suas responsabilidades em relação aos problemas socioambientais. Com isso há fortes indícios da busca por evitar danos ao meio ambiente mediante o uso de práticas produtivas mais "limpas", do desenvolvimento de produtos que não agridam ao meio ambiente e que não causem danos à saúde da população. Ademais, buscam comprometer-se com práticas voltadas ao bem-estar da sociedade ou ao menos da comunidade em que essa organização está inserida. 0 que se mostra necessário é uma revisão de seus processos decisórios.

As empresas que não respeitarem as exigências socioambientais poderão ter sérias implicações em médio e longo prazo, seja pela legislação, pagando multas e tendo que reverter os problemas causados, seja, conforme explica Boele, Fabig e Wheller (2001), pelos danos que uma marca não legítima pode causar ao reduzir em milhões de dólares o valor das ações. Além disso, podem afastar consumidores e não atrair pessoas qualificadas para seus quadros.

O estudo do processo decisório aponta ser uma grande utopia acreditar que a sustentabilidade possa acontecer sem uma mudança de paradigmas. Extremismos e lógicas decisórias evolucionárias, em que o lucro ainda é o principal motivador de ações ditas sustentáveis, mostram-se insuficientes, já que, quando se trata de sustentabilidade, os resultados financeiros podem não ser imediatos, é uma decisão que necessita de um olhar a longo prazo, vislumbrando outros ganhos, como economia de recursos naturais, retornos para a comunidade em que uma empresa está instalada. A longo prazo o retorno financeiro também acontece, mas não pode ser o principal motivador quando se trata de um processo decisório pautado na busca da sustentabilidade. Esse entendimento superficial, voltado apenas ao curto prazo e aos retornos financeiros, impede investimentos que tornem viáveis ações alinhadas à combinação "3.3", as quais abarcam os três pilares da sustentabilidade concomitantemente, gerando assim um novo sentido para o processo decisório.

Nessa direção, compreende-se que muitos problemas enfrentados pela sociedade atual, como a degradação ambiental, a escassez de recursos, a pobreza, a violência etc., poderiam ser mais bem enfrentados quando considerado o tempo e o sentido do processo decisório que levaram aos referidos acontecimentos. 
Dentro dessa perspectiva, Phillipe e Bansal (2013) acreditam que o diferencial de uma organização que possui uma lógica decisória consistente e conectada com as questões pertinentes à sustentabilidade das demais organizações é justamente levar em conta as relações espaciais e temporais. Por isso, os autores entendem que as organizações que respeitam as exigências espaço-temporal serão menos vulneráveis a mudanças externas, porque elas entendem a permeabilidade das suas fronteiras temporais e espaciais e, como tal, são capazes de desenvolver, ao longo do tempo que atravessa fronteiras, uma compreensão sistêmica e integradora de suas relações com o ambiente natural (PHILLIPE; BANSAL, 2013).

A partir desse estudo e da construção do Quadro 4, compreendemos que a abordagem da sustentabilidade nas organizações exige uma nova consciência individual e coletiva que abarque a noção de tempo e espaço, dando um novo sentido ao desenvolvimento.

Para isso, são apresentadas alternativas e implicações no referido quadro com o intuito de incitar esses novos sentidos. Sentidos estes que apontam as lógicas decisórias economicista e evolucionária como insuficientes no que se refere à legitimidade social de suas propostas. Corroborando com essa visão, Merico (2009) defende que as organizações, ao considerarem apenas a dimensão econômica na tomada de decisão, podem conseguir um desenvolvimento financeiro, porém esse tipo de modelo voltado ao desenvolvimento econômico apenas é insustentável, já que agrava ainda mais os problemas relacionados à escassez dos recursos naturais essenciais à sobrevivência na Terra e à própria capacidade de produção da organização. Willard (2014) (apud MAIA; ZUCATO, 2015) também defendem que o modelo de desenvolvimento vigente é insustentável e traz sérios riscos à sobrevivência da espécie humana.

\section{CONSIDERAÇÕES FINAIS}

É possível perceber que as posições econômicas extremistas deixam de lado as preocupações com o ambiente natural e, muitas vezes, até com o social, uma vez que o crescimento econômico não significa a eliminação da pobreza, pois os recursos muitas vezes ficam concentrados em uma minoria. Os autores deste artigo entendem também que boa parte das posições extremistas ambientais frequentemente ignoram ou deixam para segundo plano os problemas sociais.

Nesse contexto, acredita-se e sugere-se que sejam mais pertinentes as abordagens integrativas, posto que melhor se adequam às premissas do desenvolvimento por vias sustentáveis, em que são considerados em pé de igualdade os pilares econômico, ambiental e social. O paradigma pré-morfeanista parece ser utópico e difícil de ser alcançado diante do atual nível de informação que trabalha o inconsciente humano e o estilo de vida vigente na sociedade.

Após analisar as implicações para a gestão das possíveis combinações entre abordagens e perspectivas decisórias e fundamentando-se nas teorias estudadas, foi possível iluminar distinções e consequências ao se adotar determinadas abordagens combinadas com determinadas perspectivas decisórias. Com base nessa análise, foi possível atestar potenciais implicações do predomínio de alguns raciocínios na tomada de decisão quando 
se trata da sustentabilidade. Defendeu-se uma necessária vinculação, por vezes oculta, entre a lógica decisória e o alcance dos objetivos da sustentabilidade nas organizações.

Foi plausível concluir que as implicações de se adotar abordagens extremistas, que não levam em conta todos os pilares da sustentabilidade (ambiental, econômico e social), aliadas a perspectivas decisórias evolucionárias são negativas, trazendo problemas para 0 meio ambiente, para a sociedade e para as próprias empresas. Essas implicações podem acontecer em curto, médio ou longo prazo. Muitas vezes esse tipo de lógica decisória pode estar mascarado por pequenas ações ditas e até reconhecidas como sustentáveis, mas que, subsidiando-se pelas premissas da sustentabilidade, podem estar apenas saciando interesses financeiros e de imagens de "empresas verdes" no curto prazo.

Percebeu-se a necessidade de se considerar trade-offs ao adotar uma gestão sistêmica dos pilares social, econômico e ambiental. Além disso, ao analisar as combinações no Quadro 4, entendeu-se que as abordagens integrativas voltadas às perspectivas relacionais e temporais parecem aproximarem-se mais das exigências para alcançar os objetivos da sustentabilidade nas organizações. O que confirma a posição de Munck (2015) sobre a exigência de um novo olhar para o processo decisório, ou seja, um olhar que considere diferentes escalas temporais, inter-relacionamentos, trade-offs e longo prazo.

O contexto estudado ampliou e trouxe novas formas de pensar para os atores que almejam participar da jornada rumo à sustentabilidade. A sustentabilidade não deve ser concebida como uma mudança de um estado de equilíbrio para outro, mas como um horizonte a ser abordado (porém nunca alcançado), pois em qualquer momento no tempo sempre existirão "outros" no presente e no futuro para lidar com eles. Assim, o desafio para a política, a estratégia e a pesquisa não é apenas uma questão de se tornar sustentável, mas de sustentar a capacidade de embarcar em viagens desse tipo em uma base contínua (GARUD; GEHMAN, 2012, p. 992).

Assumindo que a mudança é responsabilidade de todos, este artigo assume a sua e propõe referências para reflexões e avaliações que podem subsidiar o aparecimento de novos horizontes decisórios por muitos desconhecidos. É de responsabilidade, sim, das organizações de todos os tipos, públicas, privadas e terceiro setor, um compromisso com a natureza e com toda a sociedade. 0 estudo ajuda a confirmar que já não é mais possível reforçar a utopia de um planeta com recursos infinitos e que podem ser substituídos e recuperados somente com o uso de capital financeiro convertido em tecnologias avançadas.

\section{REFERÊNCIAS}

ANDERSON, P.; TUSHMAN, M.L. Technological discontinuities and dominant designs: a cyclical model of technological change. Administrative Science Quarterly, v. 35, n. 4, 1990, p. 604-633

BANSAL, P.; DESJARDINE, M. Business sustainability: It is about time. Strategic Organization, v. 12, n. 1, 2014.

BOELE, R.; FABIG, H; WHEELER, D. Shell, Nigeria and the Ogoni. A Study in Unsustainable Development: II. Corporate Social Responsibility and Stakeholder Management Versus a 
Rights-Based Approach to Sustainable Development. Sustainable Development, v. 9, p. 121-135, 2001.

BROWN, S.; EISENHARDT, K. The art of continuous change: Linking complexity theory and time-paced evolution in relentlessly shifting organizations. Administrative Science Quarterly, v. 42, p. 1-34, 1997.

CARLILE, P. R. Transferring, translating, and transforming: An integrative framework for managing knowledge across boundaries. Organ. Sci. v. 15, n. 5, p. 555-568, 2004.

DYLLICK, T.; MUFF, K. Clarifying the meaning of sustainable business: Introducing a typology from business-as-usual to true business sustainability. Organization \& Environment, $v$. 29, p. 156-174, 2016.

DEMO, P. Metodologia do conhecimento científico. São Paulo: Atlas. 2000.

EGRI, C. P.; PINFIELD, L. T. As Organizações e a Biosfera: Ecologia e Meio Ambiente. In: STEWART, C; HARDY, C.; NORD, W.R. Handbook de Estudos Organizacionais. v. 1. São Paulo: Atlas, 1998.

GAO, J.; BANSAL, P. Instrumental and Integrative Logics in Business Sustainability. Journal of Business Ethics, v. 112, n. 2, p. 241-255, 2013.

GARUD, R.; GEHMAN, J; Metatheoretical perspectives on sustainability journeys: Evolutionary, relational and durational. Research Policy, v. 41, p. 980-995, 2012.

GARUD, R.; GEHMAN, J.; KUMARASWAMY, A. Complexity Arrangements for Sustained Innovation: Lessons from 3M Corporation. Organization Studies, v. 32, n. 6, p. 737-767, 2011.

GLADWIN, T. N.; KENNELLY, J. J.; KRAUSE, T-S. Shifting Paradigms for Sustainable Development: Implications for Management Theory and Research. The Academy of Management Review, v. 20, n. 4, p. 874-907, 1995.

GEELS, F. W. Ontologies, socio-technical transitions (to sustainability) and the multi-level perspective. Research Policy, v. 39, p. 495-510, 2010.

GENUS, A.; COLES, A.M. Rethinking the multi-level perspective of technological transitions. Research Policy, v. 37, n. 9, p. 1436-1445. 2008.

KETOLA, T. Pre-Morphean Paradigm - An Alternative to Modern and Post-Modern Paradigms of Corporate Sustainability. Sustainable Development, v. 17, p. 114-126, 2009.

LANDRUM, N. E. Stages of Corporate Sustainability: Integrating the Strong Sustainability Worldview. Organization \& Environment, v. 6, p. 1-27, 2017.

LEFF, E. Discursos sustentáveis. São Paulo: Cortez Editora, 2010.

MAIA, A. G.; PIRES, P. S. Uma Compreensão da Sustentabilidade por Meio dos Níveis de Complexidade das Decisões Organizacionais. RAM, Rev. Adm Mackenzie (Online), v. 12, n. 3, Edição Especial, 2011.

MAIA, A. G; ZUCATTO, L. C. Uma Reflexão Sobre as Influências dos Paradigmas nas decisões Organizacionais direcionadas à Sustentabilidade. In: COLÓQUIO INTERNACIONAL DE 
EPISTEMOLOGIA E SOCIOLOGIA DA CIÊNCIA DA ADMINISTRAÇÃO, 5., Florianópolis, SC. Anais .... Florianópolis, 2015.

MEBRATU, D. Sustainability and sustainable development: historical and conceptual review. Environmental Impact Assessment Review, v. 18, n. 6, p. 493-520, 1998.

MERICO, L. F. K. Economia e sustentabilidade: o que é, como se faz. São Paulo: Edições Loyola, 2009.

MEYER, A.; GABA, V.; COLWELL, K. Organizing far from equilibrium: nonlinear change in organizational fields. Organization Science, v. 16, n. 5, p. 456-473, 2005.

MUNCK, L. Gestão da Sustentabilidade em Contexto Organizacional. São Paulo, CENGAGE, 2013.

. Gestão da Sustentabilidade em Contexto Organizacional: Integrando sensemaking, narrativas e processo decisório estratégico. Organizações e Sociedade, v. 22, n. 75, p. 521-538, 2015.

PHILIPPE, D.; BANSAL, T. Embedding Environmental Actions In Time And Space: The Evolution Of Sustainability Narratives. Academy of Management Proceedings, v. 1, n. 1, 2013. https://doi.org/10.5465/ambpp.2013.151

SARÁBIA-CAVENAGHI, L. Sentido Atribuído ao Processo Decisório referente a sustentabilidade em contexto organizacional. 2016. 138 fls. Dissertação (Mestrado em Administração) - Programa de Pós-Graduação em Administração, Universidade Estadual de Londrina (UEL), Londrina, 2016. Disponível em: http://www.bibliotecadigital.uel.br/document/?code $=$ vtls000207005. Acesso em: 20 fev./2017.

SHOVE, E.; WALKER, G. Governing transitions in the sustainability of everyday life. Research Policy. v. 39, n. 4, p. 471- 476. 2010.

TAKAHASHI, A. R. W. Pesquisa Qualitativa em Administração: fundamentos, métodos e usos no Brasil. Editora Atlas. 1.ed. 2013.

VERGNE, J.P.; DURAND, R. The missing link between the theory and empirics of path dependence: Conceptual clarification, testability issue, methodological implications. Journal of Management Studies, v. 47, n. 4, p. 736-759, 2010.

VOS, R. O. Defining sustainability: a conceptual Orientation. Journal of Chemical Technology and Biotechnology, v. 82, n. 4, 334-339, 2007.

WCED. WORLD COMISSION ON ENVIRONMENT AND DEVELOPMENT. Our common future (the Brundtland report). Oxford: Oxford University Press, 1987.

Data de Submissão: 10/06/2017.

Data de Aprovação: 07/05/2018.

Creative Commons Atribuição 4.0 Internacional 